\title{
BMJ Open EQ-5D-5L and SF-6Dv2 utility scores in people living with chronic low back pain: a survey from Quebec
}

\author{
Thomas G Poder (D) , ${ }^{1,2}$ Liang Wang, ${ }^{3}$ Nathalie Carrier ${ }^{4}$
}

To cite: Poder TG, Wang L, Carrier N. EQ-5D-5L and SF-6Dv2 utility scores in people living with chronic low back pain: a survey from Quebec. BMJ Open 2020;10:e035722. doi:10.1136/ bmjopen-2019-035722

- Prepublication history and additional material for this paper are available online. To view these files, please visit the journal online (http://dx.doi. org/10.1136/bmjopen-2019035722).

Received 15 November 2019 Revised 30 April 2020 Accepted 16 July 2020

Check for updates

(C) Author(s) (or their employer(s)) 2020. Re-use permitted under CC BY-NC. No commercial re-use. See rights and permissions. Published by BMJ.

${ }^{1}$ School of Public Health, University of Montreal, Montreal, Québec, Canada

${ }^{2}$ Centre de recherche de I'IUSMM, CIUSSS de l'Est de l'île de Montréal, Montréal, Québec, Canada

${ }^{3}$ Department of Economics, Concordia University, Montreal, Québec, Canada

${ }^{4}$ Centre de recherche du CHUS, CIUSSS de I'Estrie - CHUS,

Sherbrooke, Quebec, Canada

Correspondence to

Pr Thomas G Poder;

thomas.poder@umontreal.ca

\section{ABSTRACT}

Objective To describe how chronic low back pain (CLBP) impacts on utility scores and which patients' characteristics most affect these scores in the province of Quebec.

Settings Province of Quebec, Canada.

Participants 569 adult patients with CLBP.

Methods and outcomes An online survey on low back pain was conducted between October 2018 and January 2019. The EuroQol Five Dimensions (EQ-5D-5L) and the Short Form Six Dimensions version 2 (SF-6Dv2) are two generic preference-based measures used to evaluate health-related quality of life $(\mathrm{HRQOL})$ and provide qualityadjusted life-year utility values.

Results The number of subjects who agreed to participate was 610 , but 41 were excluded because 8 had low back pain for less than 3 months and 33 did not start the survey. A total of 569 subjects were analysed, but only 410 completed the survey up to the EQ-5D-5L or SF-6Dv2 sections. Median (range) of EQ-5D-5L was 0.622 ( -0.072 to 0.905$)$, and mean (range) of SF-6Dv2 and EQ-Visual Analogue Scale was 0.561 (0.301-0.829) and $51.0(0-100)$, respectively. In all multivariate models, health or life satisfaction increased the health utility score, while pain reduced it. Co-occurring health problems were present for a majority $(68 \%)$ of participants, mainly fatigue/ insomnia (57.4\%), musculoskeletal disorder (56.2\%) and mental disorder (44\%).

Conclusion This study provided utility scores with EQ5D-5L and SF-6Dv2 in patients with CLBP in Quebec, and results were similar to other studies conducted in different settings. These values were well below those reported in the Quebec general population and highlight the association between CLBP and HRQoL.

\section{INTRODUCTION}

Low back pain (LBP) refers to pain located between the lower rib margins and the buttock creases. ${ }^{1}$ Four out of five adults will experience at least one form of LBP (pain and disability) during their lifetime. ${ }^{2} 3$ Two types of pain are included in LBP: acute pain and chronic pain. The pain is considered chronic if it lasts for more than 3-6 months. ${ }^{45}$ In Canada, the cut-off point for chronic pain is set at 3 months or more, thus following the International Classification of Diseases 11th Revision (ICD-11) classification system,

\section{Strengths and limitations of this study}

No study explored utility scores for chronic low back pain in Quebec.

- Utility scores were assessed with the EuroQol Five Dimensions and Short Form Six Dimensions version 2.

- A survey was conducted among members of a national patient organisation.

- Both English and French were considered to be representative of the population.

- A main limitation is that women were overrepresented in the survey.

which also recommend to account for pain intensity, emotional distress and interference with function, when measuring pain severity. ${ }^{6}$ Acute and chronic pain can cause a wide range of physical and mental effects, greatly affecting quality of life. ${ }^{78}$ According to several studies, chronic LBP (CLBP) currently affects between $20 \%$ and $30 \%$ of the population, ${ }^{59-11}$ a majority being women. ${ }^{912}$

As CLBP affects health-related quality of life (HRQoL) and represents a societal burden, ${ }^{13}$ it is appropriate to perform cost utility analysis (CUA) to aid in decision-making (ie, clinical and organisational decision to manage CLBP). EuroQol Five Dimensions (EQ-5D) and Short Form Six Dimensions (SF-6D) are two generic preference-based measures largely used in CUA. These instruments provide utility values that are used to calculate gains in quality-adjusted life year (QALY). ${ }^{1415}$ The EQ-5D and SF-6D have been used and validated in different LBP populations, ${ }^{8} 16-18$ but not in Quebec. Recently, a new version of the SF-6D was developed (ie, SF-6Dv2) that includes only 10 items from the SF-36v2 that can be rephrased into six questions. ${ }^{19-21}$ This new version of the SF-6D has never been used patients with CLBP. Since some health technology assessment agencies recommend using local data to perform economic evaluation, especially data modelling, it is 
worthwhile to provide utility values in CLBP specific to each jurisdiction. ${ }^{22}{ }^{23}$ This is all the more important for Quebec because its population is different from other Canadian provinces. Not only Quebec is the only Canadian province that has a predominantly French-speaking population, ${ }^{24}$ but also showing different results in terms of health indicators. ${ }^{25}$ In addition, since the decision of the Supreme Court of Canada in 2014, people of Quebec is recognised as a distinct society within Canada. ${ }^{26}$

The main purpose of this article was to describe health state utility scores with EQ-5D-5L and SF-6Dv2 in patients with CLBP in Quebec. Another objective was to describe health state utility scores stratified for various sociodemographic data, types of diagnoses and kinds of pain management. Predictors of health state utility scores for EQ-5D-5L index, EQ-Visual Analogue Scale (VAS) and SF-6Dv2 were also explored.

\section{METHODS \\ Data}

The data come from an online survey on LBP conducted between October 2018 and January 2019. The objective of the survey was to perform a discrete choice experiment (DCE) about preference of patients with CLBP for nonsurgical treatments. ${ }^{27}$ To note that the results of the DCE are not presented in this article. The Quebec Association of Chronic Pain (Association Québécoise de la douleur chronique-AQDC) distributed by email to its members the link to the online survey, and posters with this information were also placed at different outpatient clinics in our institution. No monetary compensation was offered for completing the survey. The inclusion criteria were to be a Quebec resident, at least 18 years old, who suffers from LBP. Subjects with LBP for less than 3 months, unable to complete an online questionnaire by themselves or with help, or unable to read either French or English were excluded.

\section{Survey}

The first page of the survey presented the aim of the survey content, advantages and disadvantages for the participant, and the name of a contact person for questions or complaints. The questionnaire included sociodemographic data, self-reported medical back pain diagnosis, intensity of LBP (pain today, worst pain and average level of pain in the last 2 weeks) on a scale from 0 to 10 , treatments other than medication, insurance, other diseases or physical or mental issues that diminish quality of life and general health on a five-point Likert scale from excellent to poor. Health and life satisfaction scores and willingness to take risks were measured with a Likert scale from 0 to 10 corresponding, respectively, to not at all satisfied to fully satisfied and from hate taking risks to love taking risks. A series of 12 choice cards for the DCE were also presented, following the methodology recommended by the International Society for Pharmacoeconomics and Outcomes Research (ISPOR). ${ }^{28}$ The survey ended with four HRQoL questionnaires that were administered in a random order: EQ-5D-5L, SF-6Dv2, Roland Morris Disability Questionnaire and Oswestry Disability Questionnaire (only the two first questionnaires are presented here). The survey is available in online supplementary file 1 .

\section{Outcomes}

\section{EQ-5D-5L}

The EQ-5D-5L is widely used to measure QALYs. This questionnaire (English-Canadian and French-Canadian version) includes five dimensions (mobility, self-care, usual activities, pain/discomfort and anxiety/depression) with five levels each, from no problem to extreme problem. The EQ-5D-5L questionnaire also includes a vertical VAS with 100 on the top representing the 'best imaginable health state' and 0 at the bottom representing the 'worst imaginable health state'. Health utility scores were calculated with the value set developed by Xie $e t a l,{ }^{29}$ and their recommended model was used. The health utilities elicited ranged from -0.148 for the worst $(55555)$ to 0.949 for the best (11111) EQ-5D-5L health states. Since health utility scores were calculated using a linear model, worst and best states were different from 0 and 1 .

\section{SF-6Dv2}

The SF-6D is a multiattribute utility instrument derived from the SF-36 quality-of-life questionnaire. The SF-6Dv2 is a new version of the SF-6D that contains only 10 items from the SF-36 that may be rephrased into six questions, that is, one item per dimension (physical functioning, role limitations, social functioning, pain, mental health and vitality). Each item has five levels, except pain with six levels. Since a value set is neither available for Quebec nor for the SF-6Dv2, health utility scores were calculated with the value set model 2 developed for the UK by Brazier and Roberts. ${ }^{30}$ The health utilities elicited ranged from 0.301 to 1 , corresponding to the worst (555655) and the best (111111) health states. The main difference between the EQ-5D-5L and the SF-6Dv2 is that the last one includes more HRQoL dimensions. In the SF-6Dv2, the two first dimensions of the EQ-5D-5L (mobility and self-care) are merged into one (physical functioning), thus allowing to include two more dimensions not assessed in the EQ-5D-5L, namely social functioning and vitality.

\section{Statistical analysis}

A histogram of health utility scores was used to evaluate normality distribution. Results were presented with mean (95\% CI) for EQ-VAS and SF-6Dv2 and with median (IQR) for EQ-5D-5L. Health utility scores were compared by sociodemographic characteristics, health status, health and life satisfaction, willingness to take risks, diagnosis, pain intensity and treatment and management of pain. Analysis of variance or Student's t-test was used for utility scores normally distributed, otherwise Kruskal-Wallis or Mann-Whitney was used. The rate of problems affecting HRQoL was also described for the complete cohort. Ceiling and floor effects were calculated for each utility 
instrument. Ceiling effect was the proportion of respondents reporting 'no problems' for all dimensions, and floor effect was the proportion of respondents reporting the worst level for all dimensions. Multivariate linear models with stepwise selection were performed to predict EQ-5D-5L, EQ-VAS and SF-6Dv2 utility scores. Explanatory variables were not transformed and were used as binary (noted as 1-0) or continuous (noted as continuous or $0-10$ ). Only variables with $\mathrm{p}<0.1$ in univariate analysis were included, and only variables with $\mathrm{p}<0.05$ in multivariate model were retained. Since the EQ-5D-5L was not normally distributed, the model was applied on inverse $\operatorname{logarithm}$ utility score transformation $(\log (\mathrm{x}-1))$. Therefore, the estimates of the models must be interpreted in the opposite direction. As the EQ-5D-5L and SF-6Dv2 were at the end of the survey, and as the subjects were obliged to answer each question before going on to the next, the subjects with values for EQ-5D-5L and SF-6Dv2 answered all the previous questions. So, no imputation was done for missing data. Normality of residues was validated. Analyses were computed with SAS software (V.9.4; SAS Institute) and graphs with GraphPad Prism V.7.00 for Windows. A p value less than 0.05 was considered significant.

\section{Patient and public involvement}

Patients were involved in the study in the following ways: (1) conception of the questionnaire survey; (2) critical revision of the questionnaire survey; (3) participation to recruitment through the AQDC.

\section{RESULTS}

\section{Sample characteristics}

Between October 2018 and January 2019, 610 subjects responded to questionnaire. There were 41 subjects excluded, 8 because they had LBP for less than 3 months and 33 who did not start the survey. Out of 569 subjects analysed, only 410 completed the survey up to the EQ-5D-5L or SF-6Dv2. Subjects who did not complete their health state with EQ-5D-5L and SF-6Dv2 were older, had slightly lower body mass indexes (BMIs), were more likely to be widowers, more likely to be retired, had more osteoporosis, did less aerobic activity and were more likely to have had a stroke. No difference was observed for education, income, pain, treatments, health status or life/health satisfaction (see online supplementary table $1)$. For subjects who went to the end of the survey, the median time to complete the questionnaire was $34 \mathrm{~min}$. The mean (range) age was 56 (18-89) years; the majority were women $(78.9 \%) ; 13.3 \%$ were smokers; education level was higher than the general population $(43.3 \%$ at university vs $25.5 \%)^{31}$; but fewer were employed (24.9\%) compared with the general population (59.5\%). A majority of participants (94.3\%) completed the French version of the survey even though an English version was available. This is slightly fewer than the $9 \%$ of the
Quebec population who consider English as their native language. $^{32}$

\section{Distribution of EQ-5D-5L and SF-6Dv2 utility scores and EQ- VAS}

Index score of EQ-5D-5L was not normally distributed, but those of SF-6Dv2 and EQ-VAS were normally distributed (figure 1). Median (range) of EQ-5D-5L was 0.622 $(-0.072$ to 0.905$)$, and mean (range) of SF-6Dv2 and EQ-VAS was $0.561(0.301-0.829)$ and $51.0 \quad(0-100)$, respectively. There was no ceiling effect for EQ-5D-5L and SF-6Dv2 (ie, value of 0.949 or 1 , respectively). Only one subject had a score of 100 for the EQ-VAS. There was no floor effect for EQ-5D-5L (ie, -0.148), four subjects for EQ-VAS and two for SF-6Dv2 (ie, value at 0.301). When each dimension was analysed, higher levels were observed for pain, vitality, role limitations and usual activity. For EQ-5D-5L, 88.3\% had moderate-to-extreme pain (level 3 or more), and $37.8 \%$ had severe-to-extreme pain (level of 4 or 5 ). For SF-6Dv2, $99.7 \%$ had moderate to very severe pain (level 3-6), and 59.8\% had severe or very severe pain (level 5 or 6 ; see online supplementary table 2 ).

\section{EQ-5D-5L and SF-6Dv2 utility scores and EQ-VAS according to sample characteristics}

Scores varied significantly by age, but they did not decrease as age increased as may be expected in the general population (table 1). Women, subjects with nonobese BMIs, employed subjects and subjects owning a home had significantly higher utility scores. Utility scores significantly increased with better health status and with health and life satisfaction. Marital status, education, living with an adult and willingness to take risks had no impact on EQ-5D-5L, EQ-VAS or SF-6Dv2. As expected, subjects with more pain had lower utility scores (table 2). Similarly, subjects who used pain medication several times a day had the lowest scores, but those who never used pain medication also had low scores. Considering management of pain, subjects who used medical marijuana had lower utility scores, while subjects who practice endurance activities, strength training, relaxation, meditation and body-mind activities had higher utility scores.

\section{Problems affecting HRQoL}

A majority (68\%) of participants self-reported having other problems affecting their HRQoL (table 3). The most frequent problems observed other than pain were fatigue or insomnia (57.4\%), musculoskeletal disorder (52.2\%; mainly defined by osteoarthritis $(44.0 \%)$ ) and mental disorder (44\%). About a quarter also had cardiac, gastrointestinal or endocrine disorders. Respiratory disorder was present in $13.3 \%$ of subjects.

\section{Predictors of EQ-5D-5L, EQ-VAS and SF-6Dv2}

One multivariate linear regression model by outcome was performed to explore predictors of utility scores (table 4). EQ-5D-5L index had more predictors than other instruments. Since EQ-5D-5L was transformed with inverse logarithm to obtain a normal distribution 
A

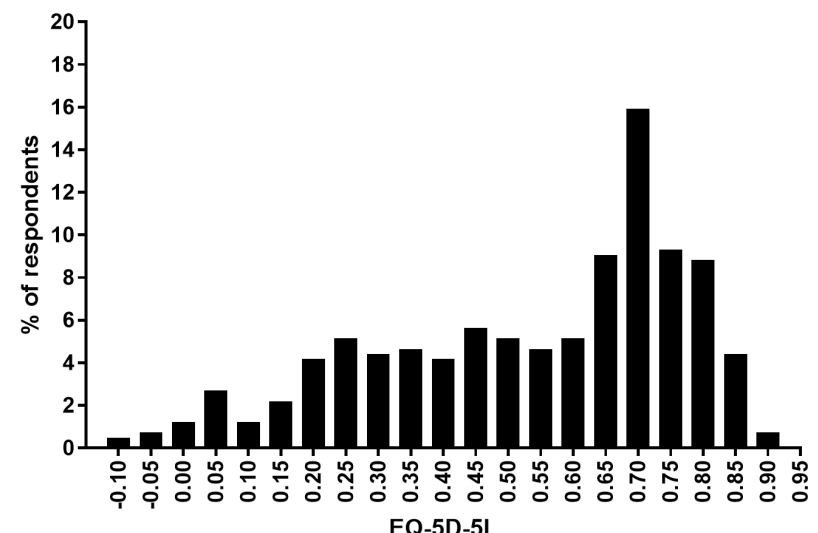

B

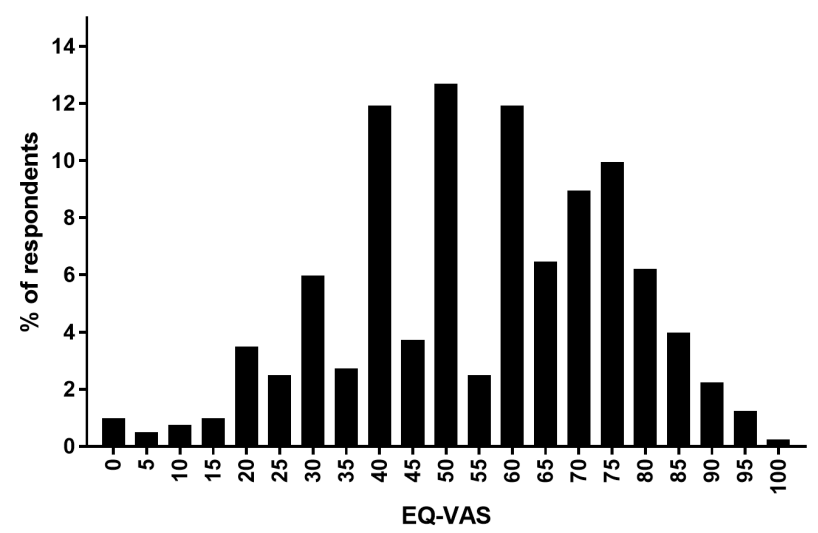

C

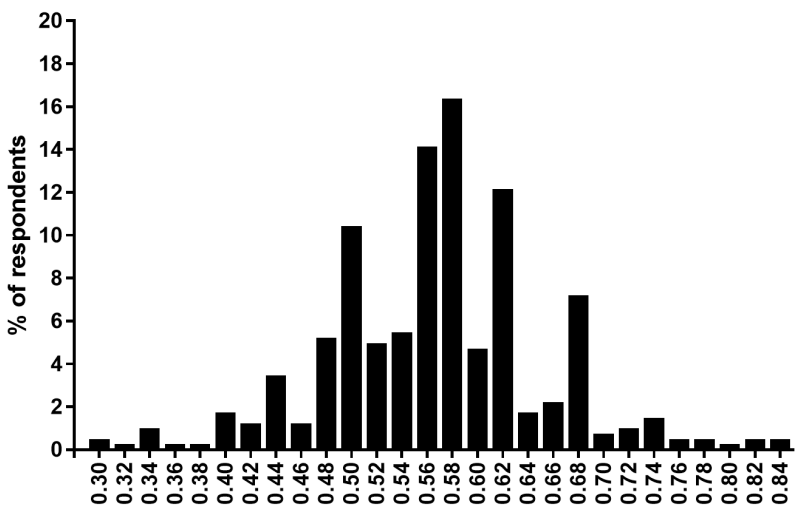

SF6Dv2

Figure 1 Distribution of utility scores and Visual Analogue Scale (VAS) for EuroQol Five Dimensions (EQ-5D-5L) and Short Form Six Dimensions version 2 (SF-6Dv2). The values on the $\mathrm{x}$-axis correspond to the central value with an interval of 0.05 for EQ-5D-5L score, 5 points for EQ-VAS and 0.02 point for SF-6Dv2. There was no ceiling effect for EQ-5D-5L and SF-6Dv2. Only one subject had a score of 100 for EQVAS. There was no floor effect for EQ-5D-5L, four subjects for EQ-VAS and two for SF-6Dv2.

of residues, the estimates must be interpreted in the opposite sense. In all models, health or life satisfaction increased the health utility score, while pain reduced it. Self-reported good health increased the EQ-5D-5L index, but poor/fair health status decreased the EQ-VAS and SF-6Dv2 utility scores. Considering CLBP treatment, an osteopathy session was a predictor of EQ-5D-5L index, and body-mind activities other than yoga were predictors of EQ-5D-5L and SF-6Dv2. As to occupational status, being employed or retired increased EQ-5D-5L, but sick leave reduced SF-6Dv2. Occupational status and treatment had no impact on EQ-VAS. Regarding other sociodemographic data, living in an urban area and having a lower BMI increased the EQ-5D-5L index, and having a child increased the SF-6Dv2. Patients with osteoporosis had higher EQ-VAS values compared with other diagnoses.

\section{DISCUSSION}

This study examined health state utility scores with EQ-5D-5L and SF-6Dv2 in patients with CLBP in Quebec, a French-speaking province of Canada. It described health-state utility scores for various sociodemographic data, types of diagnoses and kinds of pain management. To our knowledge, this is the first Quebec study to report EQ-5D-5L and SF-6Dv2 utility scores in patients with CLBP. The population norms produced in this study for patients with CLBP will be very helpful in feeding models aimed at predicting the impact of interventions on such patients. ${ }^{3334}$ Indeed, to our knowledge, no representative portrait of people living with CLBP has been conducted in Quebec, although some initiative exists with their geographical and inclusion criteria limits. ${ }^{35}$ As a consequence, it is hard to say how close is our survey to a representative sample of this population. However, since our survey was mainly conducted with members of the AQDC, which is a provincial-wide patient organisation, without any geographical limitation, we believe that our sample is representative of most people with CLBP in Quebec who are able to complete a survey in French or English.

As expected, the median value of EQ-5D-5L and EQ-VAS was lower than what we obtained as the reference value for the general population in Quebec (adjusted for age and gender). The results for population norms previously published were 0.245 points higher for the EQ-5D-5L (median 0.867 (IQR 0.802-0.911)) and 25 points higher for the EQ-VAS (75.9 (75.2-76.6)). ${ }^{36}$ Moreover, our results were close to those of other studies of populations with LBP. In the study by Ye et al, EQ-5D-5L and SF-6D distributions were similar but slightly higher than our results (median (IQR) $0.702(0.438,0.862)$ ) and mean score 0.593 (SD 0.143), respectively. ${ }^{16}$ As they recruited Chinese patients in a hospital, we could have expected them to have lower health-state utility scores; this may be due to cultural differences. Furthermore, they had many more men $(62 \%)$ than in our cohort $(20.7 \%)$, which is contrary to the epidemiology of the disease. $^{29}$ Cheung et al studied Chinese patients, and their results were more similar to ours (mean EQ-5D-5L index of 0.664 (SD 0.204) and mean SF-6D of 0.573 (SD $0.119)$ ), but their subjects had less pain when considering the dimension pain/discomfort of EQ-5D-5L. ${ }^{17}$ The lower degree of pain could explain why their EQ-5D-5L utility scores were slightly higher than in our study. Finally, a 
Table 1 Sociodemographic characteristics

\begin{tabular}{|c|c|c|c|c|c|c|c|}
\hline & \multirow{2}{*}{$\begin{array}{l}n(\%) \text { or } \\
\text { mean } \pm S D\end{array}$} & \multicolumn{2}{|c|}{ EQ-5D-5L index } & \multicolumn{2}{|c|}{ EQ-VAS } & \multicolumn{2}{|c|}{ SF-6Dv2 } \\
\hline & & $\mathbf{n}$ & Median (IQR) & $\mathbf{n}$ & Mean $(95 \% \mathrm{Cl})$ & $\mathbf{n}$ & Mean $(95 \% \mathrm{Cl})$ \\
\hline Overall & & 408 & $0.622(0.369-0.745)$ & 402 & 51.0 (48.8 to 53.2) & 403 & 0.561 (0.553 to 0.569$)$ \\
\hline$<35$ & $25(4.5)$ & 19 & $0.531(0.301-0.707)^{*}$ & 18 & $40.7(30.9 \text { to } 50.6)^{\star}$ & 18 & $0.523(0.491 \text { to } 0.556)^{*}$ \\
\hline $35-39$ & $31(5.5)$ & 26 & $0.678(0.365-0.738)$ & 26 & 52.5 (45.1 to 59.9 ) & 26 & 0.552 (0.529 to 0.576$)$ \\
\hline $50-54$ & $80(14.3)$ & 60 & $0.568(0.206-0.707)$ & 58 & 51.7 (45.6 to 57.9 ) & 58 & $0.539(0.516$ to 0.563$)$ \\
\hline $55-59$ & $87(15.5)$ & 68 & $0.638(0.405-0.745)$ & 67 & 55.0 (49.7 to 60.3$)$ & 66 & 0.574 (0.551 to 0.596$)$ \\
\hline $60-64$ & $71(12.7)$ & 49 & $0.661(0.475-0.803)$ & 49 & 57.7 (52.2 to 63.2) & 50 & 0.569 (0.547 to 0.592$)$ \\
\hline $65-69$ & $76(13.6)$ & 54 & $0.706(0.513-0.784)$ & 54 & 61.0 (55.8 to 66.2 ) & 54 & 0.587 (0.563 to 0.612$)$ \\
\hline Range & $18-89$ & & & & & & \\
\hline \multicolumn{8}{|l|}{ Gender $(n=569)$} \\
\hline Men & $118(20.7)$ & 83 & $0.578(0.310-0.726)^{\star}$ & 83 & $52.2(47.5$ to 56.9$) \dagger$ & 81 & 0.556 (0.537 to 0.575$) \neq$ \\
\hline Women & $449(78.9)$ & 323 & $0.660(0.399-0.746)$ & 317 & 56.4 (54.2 to 58.6$)$ & 320 & $0.563(0.554$ to 0.573$)$ \\
\hline Intersex & $2(0.4)$ & 2 & $0.065(0.001-0.130)$ & 2 & $15.0(-48.5$ to 78.5$)$ & 2 & 0.430 (0.067 to 0.792$)$ \\
\hline \multicolumn{8}{|c|}{ Body mass index $\left(\mathrm{kg} / \mathrm{m}^{2}\right)(\mathrm{n}=556)$} \\
\hline$<18.5$ & $10(1.8)$ & 6 & $0.645(0.454-0.706)^{\star}$ & 6 & $60.0(46.7 \text { to } 73.3)^{*}$ & 6 & $0.592(0.534 \text { to } 0.649)^{\star}$ \\
\hline $18.5-24.9$ & $151(27.2)$ & 100 & $0.676(0.434-0.765)$ & 100 & 61.3 (57.5 to 65.0$)$ & 100 & 0.581 (0.564 to 0.598$)$ \\
\hline $25-29.9$ & $194(34.9)$ & 146 & $0.645(0.401-0.763)$ & 141 & 54.5 (51.1 to 58.0$)$ & 141 & 0.553 (0.539 to 0.568$)$ \\
\hline Yes & $70(13.3)$ & 54 & $0.560(0.310-0.706)^{\star}$ & 52 & 51.8 (46.5 to 57.1$)$ & 51 & 0.540 (0.513 to 0.567$) \ddagger$ \\
\hline No & $456(86.7)$ & 354 & $0.652(0.372-0.750)$ & 350 & 55.8 (53.7 to 58.0$)$ & 352 & 0.564 (0.555 to 0.573$)$ \\
\hline \multicolumn{8}{|l|}{ Marital status $(n=557)$} \\
\hline Married/common law & $327(58.7)$ & 246 & $0.625(0.411-0.745)$ & 245 & 55.8 (53.4 to 58.3$)$ & 244 & 0.564 (0.554 to 0.574$)$ \\
\hline Single & $97(17.4)$ & 71 & $0.576(0.372-0.726)$ & 70 & 55.2 (50.8 to 59.6$)$ & 71 & 0.558 (0.539 to 0.577$)$ \\
\hline Divorced/separated & $107(19.2)$ & 78 & $0.618(0.301-0.736)$ & 75 & $54.0(48.5$ to 59.5$)$ & 76 & 0.558 (0.532 to 0.583$)$ \\
\hline Widowed & $26(4.7)$ & 13 & $0.637(0.271-0.763)$ & 12 & 54.2 (37.5 to 70.9$)$ & 12 & 0.541 (0.492 to 0.590$)$ \\
\hline \multicolumn{8}{|l|}{ Occupational status $(\mathrm{n}=555)$} \\
\hline Employed & $138(24.9)$ & 110 & $0.718(0.622-0.765) \S$ & 108 & $59.4(55.8$ to 63.0$) \dagger$ & 108 & $0.578(0.561$ to 0.595$) \S$ \\
\hline Student & $13(2.3)$ & 8 & $0.493(0.317-0.706)$ & 8 & 53.8 (34.2 to 73.3 ) & 8 & 0.557 (0.522 to 0.592$)$ \\
\hline Retired & $218(39.3)$ & 141 & $0.668(0.457-0.764)$ & 140 & 57.9 (54.5 to 61.3$)$ & 141 & 0.585 (0.571 to 0.599$)$ \\
\hline At home & $30(5.4)$ & 22 & $0.619(0.335-0.672)$ & 21 & 51.1 (42.7 to 59.6$)$ & 22 & 0.528 (0.494 to 0.562$)$ \\
\hline Unemployed & $16(2.9)$ & 12 & $0.498(0.251-0.661)$ & 12 & 46.7 (33.6 to 59.8 ) & 11 & $0.543(0.500$ to 0.586$)$ \\
\hline On sick leave, parental leave & $73(13.2)$ & 57 & $0.411(0.270-0.637)$ & 57 & 48.6 (43.3 to 53.9$)$ & 57 & $0.519(0.499$ to 0.538$)$ \\
\hline Invalid & $67(12.1)$ & 58 & $0.430(0.280-0.580)$ & 56 & $51.6(45.7$ to 57.5$)$ & 56 & 0.529 (0.509 to 0.549$)$ \\
\hline \multicolumn{8}{|l|}{ Education $(n=555)$} \\
\hline Secondary or less & $81(14.6)$ & 57 & $0.522(0.353-0.736) \ddagger$ & 57 & 52.5 (46.9 to 58.0$)$ & 57 & 0.557 (0.535 to 0.579$)$ \\
\hline Professional diploma & $81(14.6)$ & 61 & $0.570(0.316-0.707)$ & 60 & 52.1 (46.9 to 57.2 ) & 60 & 0.545 (0.523 to 0.567$)$ \\
\hline
\end{tabular}


Table 1 Continued

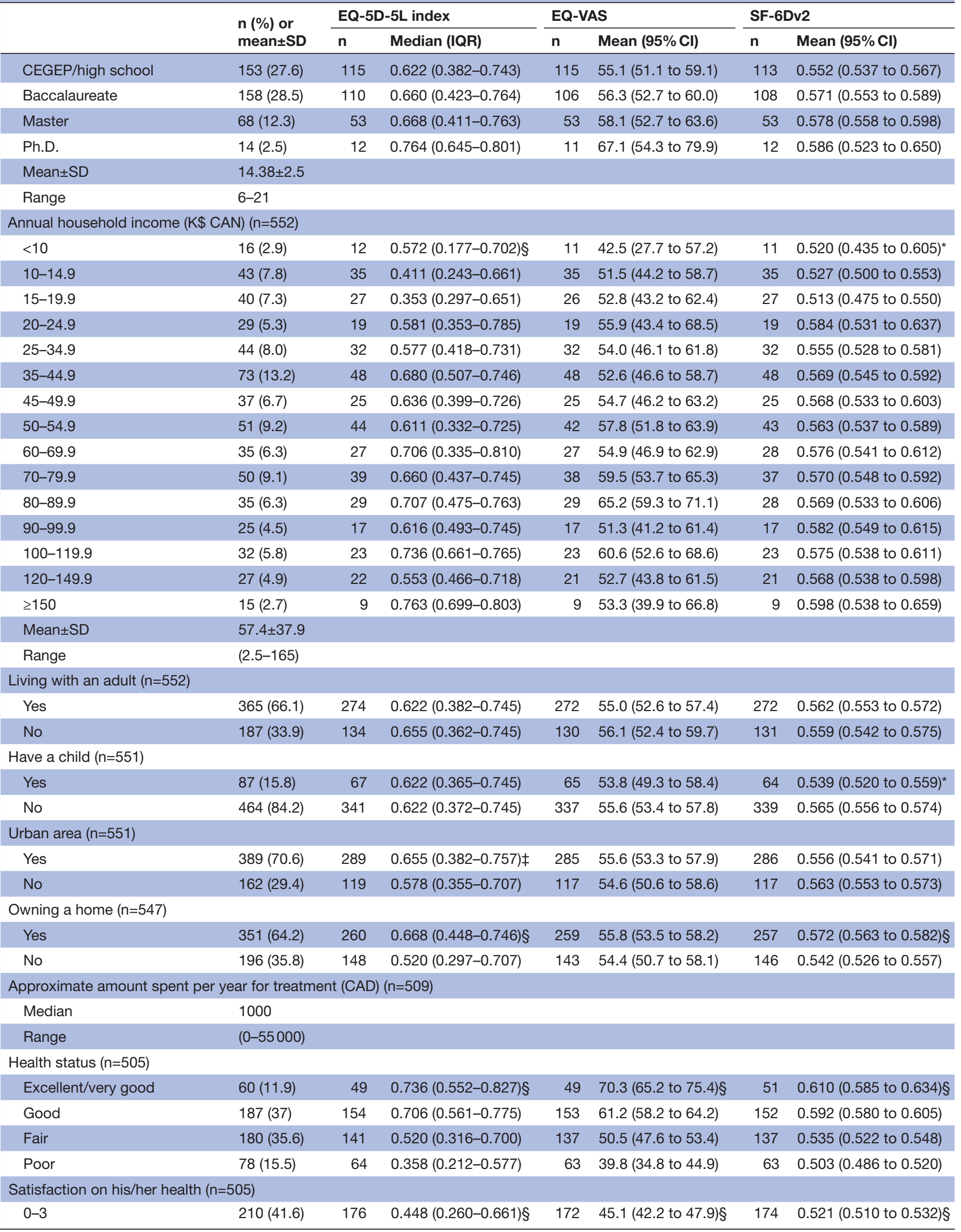


Table 1 Continued

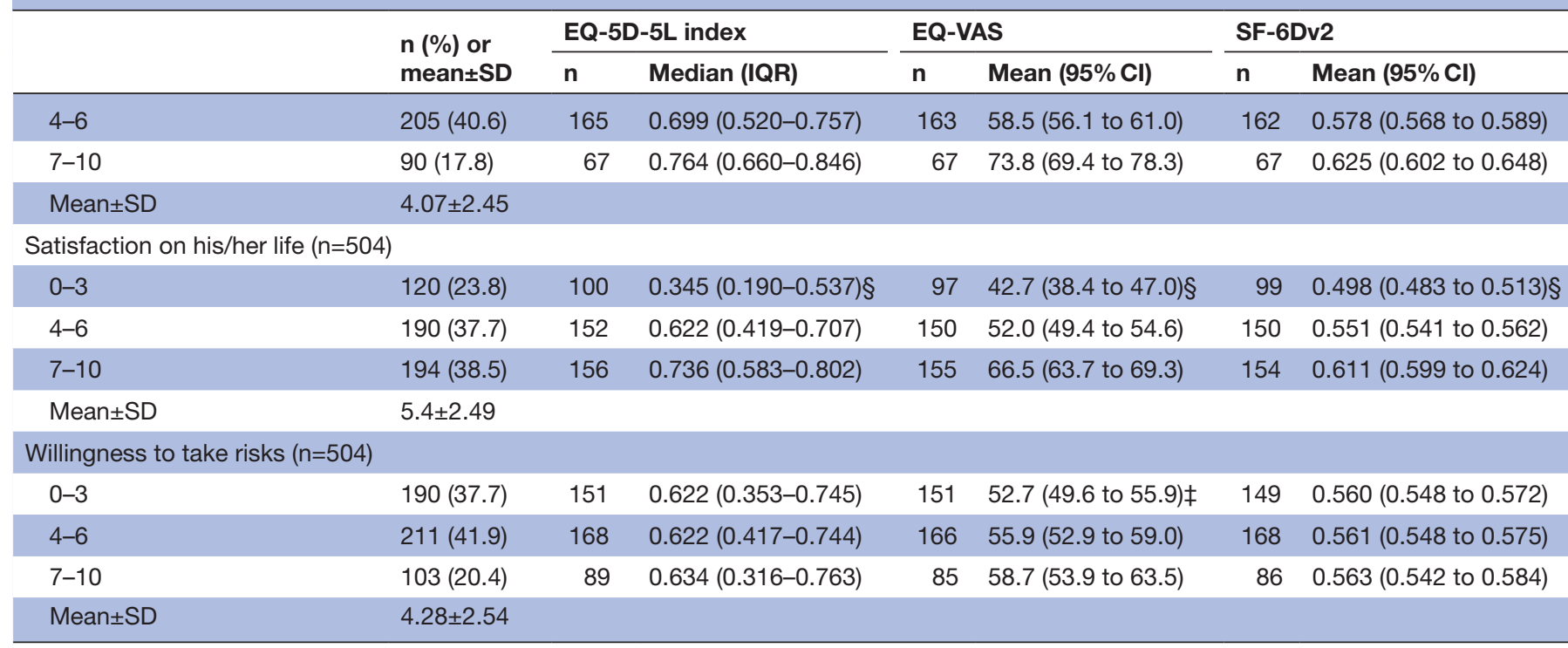

Omnibus test for statistical significance between groups:

${ }^{*} \mathrm{P}<0.05$.

$\dagger P<0.01$

$\neq \mathrm{P}<0.1$.

$\S P<0.001$.

EQ-5D-5L, EuroQol Five Dimensions; SF-6Dv2, Short Form Six Dimensions version 2; VAS, Visual Analogue Scale.

study by Søgaard et al found slightly higher EQ-5D-3L (median=0.691) and SF-6D (mean=0.677) utility scores, but their patients had undergone spinal surgery. ${ }^{37}$

Another objective of the study was to identify predictors of health-state utility scores for EQ-5D-5L index, EQ-VAS and SF-6Dv2. Some predictors were present in all models: health and life satisfaction were associated with better utility scores; good/poor health status was associated with better/lower utility scores, and pain was associated with lower utility scores. Body-mind activities were also associated with higher EQ-5D-5L and SF-6Dv2 utility scores, but not with EQ-VAS values. In multivariate models, age, gender, education, smoking and income had no impact on utility scores. To note that some predictors were tapping the same concepts incorporated in the utility instrument, such as pain, and logically showed a correlation.

Our cohort includes a majority of women, but men had lower utility scores in univariate analysis even though it was not a predictor in multivariate models. There were more subjects who were invalid or on sick leave than in the general population, and this is a negative predictor of SF-6Dv2 utility scores. To be employed is a predictor of higher EQ-5D-5L utility scores. It is not clear if there are specific age categories with higher or lower EQ-5D-5L and SF-6Dv2 utility scores as it was not a predictor in multivariate models. There were fewer smokers than in the general population, and smokers had lower utility scores in univariate analysis. We did not have questions about physical activities other than for pain management, but body-mind activities were associated with higher EQ-5D-5L and SF-6Dv2 utility scores in multivariate models, and subjects who used physical activities for management of pain had higher utility scores. Some studies suggested that obesity or high BMI were risk factors ${ }^{98}{ }^{39}$; others do not see an association. ${ }^{40} 41$ In our cohort, a higher BMI was associated with lower utility scores only for the EQ-5D-5L.

As demonstrated in other studies, LBP is associated with the co-occurring of other chronic conditions. $^{2} 5$ 42-47 In our cohort, two-thirds considered that they have other health problems, compared with a study by Pagé et al where only one-third of their Quebec cohort had comorbidity. ${ }^{5}$ Pagé et al performed a very large study with 3966 patients. ${ }^{5}$ Their study had a lower proportion of women, and their most prevalent pain diagnoses were chronic musculoskeletal pain $(37.9 \%)$ and chronic neuropathic pain $(32.2 \%)$. As these diagnoses are non-specific, they were not used in our study. Our most prevalent pain diagnoses were herniated lumbar disk (37.3\%), facet osteoarthritis $(35.6 \%)$ and fibromyalgia $(34.6 \%)$. However, in our cohort, when considering other problems affecting HRQoL, $56 \%$ of respondents reported having a musculoskeletal disorder, principally osteoarthritis, and in other studies LBP is frequently associated with musculoskeletal disorders like arthritis, osteoarthritis and osteoporosis. ${ }^{43} 47$ As in our cohort, LBP is associated with anxiety and sleep disorder ${ }^{43}$ or depression and other psychological disorders. ${ }^{42} 4346$ Other comorbidities observed in our cohort and in the literature are the presence of cardiovascular disease ${ }^{45}$ and respiratory disorder. ${ }^{445}$

A strength of our study is that our results and distribution of utility scores are similar to other cohorts with the 
Table 2 Diagnosis, pain, treatment and management of pain

\begin{tabular}{|c|c|c|c|c|c|c|c|}
\hline & \multirow{2}{*}{$\begin{array}{l}n(\%) \text { or } \\
\text { mean } \pm S D\end{array}$} & \multicolumn{2}{|c|}{ EQ-5D-5L index } & \multicolumn{2}{|c|}{ EQ-VAS } & \multicolumn{2}{|c|}{ SF-6Dv2 } \\
\hline & & $\mathbf{n}$ & Median (IQR) & $\mathbf{n}$ & Mean $(95 \% \mathrm{Cl})$ & $\mathbf{n}$ & Mean $(95 \% \mathrm{Cl})$ \\
\hline \multicolumn{8}{|c|}{ Diagnosis given by a physician $(n=523)$} \\
\hline Herniated lumbar disk & $195(37.3)$ & 158 & $0.577(0.355-0.736)^{\star}$ & 155 & 53.3 (49.9 to 56.6$)$ & 153 & 0.554 (0.541 to 0.568$)$ \\
\hline Facet osteoarthritis & $184(35.2)$ & 145 & $0.590(0.382-0.736)$ & 141 & 54.7 (51.5 to 58.0$)$ & 143 & $0.551(0.537 \text { to } 0.564)^{\star}$ \\
\hline Degenerative disk disease & $98(18.7)$ & 79 & $0.561(0.335-0.706) \ddagger$ & 77 & 54.1 (49.1 to 59.1$)$ & 76 & $0.542(0.522$ to 0.562$) \ddagger$ \\
\hline $\begin{array}{l}\text { Spinal osteoarthritis, } \\
\text { spondyloarthrosis }\end{array}$ & $83(15.9)$ & 66 & $0.600(0.399-0.718)$ & 66 & 56.0 (51.1 to 60.9$)$ & 65 & 0.551 (0.531 to 0.572$)$ \\
\hline Deformations & $65(12.4)$ & 46 & $0.597(0.280-0.736)$ & 45 & 59.0 (52.9 to 65.2$)$ & 46 & 0.559 (0.526 to 0.593$)$ \\
\hline $\begin{array}{l}\text { Autoimmune inflammatory } \\
\text { disease }\end{array}$ & $31(5.9)$ & 26 & $0.679(0.271-0.743)$ & 25 & $51.0(41.4$ to 60.6$)$ & 26 & 0.541 (0.504 to 0.578$)$ \\
\hline Stenosis & $17(3.3)$ & 15 & $0.580(0.399-0.764)$ & 14 & 57.4 (42.4 to 72.3$)$ & 14 & $0.537(0.473$ to 0.602$)$ \\
\hline Spinal fracture or dislocation & $15(2.9)$ & 11 & $0.423(0.090-0.706)$ & 11 & 57.3 (40.0 to 74.6 ) & 11 & $0.543(0.457$ to 0.629$)$ \\
\hline Chronic pain & $8(1.5)$ & 6 & $0.676(0.622-0.707)$ & 6 & 47.2 (27.3 to 67.0$)$ & 6 & $0.553(0.502$ to 0.603$)$ \\
\hline Neurological disease & $6(1.2)$ & 5 & $0.501(0.423-0.577)$ & 5 & 57.0 (40.2 to 73.8$)$ & 5 & $0.543(0.483$ to 0.603$)$ \\
\hline $\begin{array}{l}\text { Osteoporosis with spinal } \\
\text { fracture }\end{array}$ & $6(1.2)$ & 5 & $0.355(0.347-0.661)$ & 5 & 53.0 (34.6 to 71.4$)$ & 5 & 0.594 (0.519 to 0.668$)$ \\
\hline Other vertebral problem & $10(1.9)$ & 9 & $0.616(0.362-0.707)$ & 9 & 56.6 (41.3 to 71.8$)$ & 9 & $0.546(0.472$ to 0.620$)$ \\
\hline \multicolumn{8}{|c|}{ Intensity of pain today $(0-10 \mathrm{~cm})(\mathrm{n}=518)$} \\
\hline $0-3$ & $92(17.8)$ & 74 & $0.745(0.616-0.846) \S$ & 73 & $65.9(61.4$ to 70.4$) \S$ & 74 & $0.611(0.591$ to 0.631$) \S$ \\
\hline $4-6$ & $244(47.1)$ & 191 & $0.668(0.411-0.746)$ & 191 & 56.7 (54.1 to 59.4$)$ & 189 & $0.566(0.555$ to 0.577$)$ \\
\hline $7-10$ & $182(35.1)$ & 143 & $0.439(0.243-0.660)$ & 138 & 47.8 (44.3 to 51.3$)$ & 140 & $0.528(0.514$ to 0.542$)$ \\
\hline Mean $\pm S D$ & $5.48 \pm 2.03$ & & & & & & \\
\hline \multicolumn{8}{|c|}{ Worst level of pain in the last 2 weeks $(0-10 \mathrm{~cm})(n=518)$} \\
\hline $0-3$ & $12(2.3)$ & 7 & $0.867(0.466-0.885) \S$ & 7 & $67.6(44.2$ to 91.0$) \S$ & 7 & 0.661 (0.568 to 0.755$) \S$ \\
\hline $4-6$ & $114(22)$ & 91 & $0.718(0.608-0.810)$ & 91 & $61.3(57.4$ to 65.3$)$ & 91 & 0.609 (0.593 to 0.625$)$ \\
\hline $7-10$ & $392(75.7)$ & 310 & $0.576(0.316-0.726)$ & 304 & 53.2 (51.0 to 55.5$)$ & 305 & $0.545(0.536$ to 0.554$)$ \\
\hline Mean \pm SD & $7.58 \pm 1.87$ & & & & & & \\
\hline \multicolumn{8}{|c|}{ Average level of pain in the last 2 weeks $(0-10 \mathrm{~cm})(n=517)$} \\
\hline $0-3$ & $75(14.5)$ & 55 & $0.765(0.668-0.859) \S$ & 55 & 64.2 (58.6 to 69.8$) \S$ & 55 & $0.620(0.598$ to 0.642$) \S$ \\
\hline $4-6$ & $281(54.4)$ & 224 & $0.644(0.396-0.745)$ & 221 & 56.5 (54.0 to 59.0$)$ & 223 & 0.566 (0.556 to 0.577$)$ \\
\hline $7-10$ & $161(31.1)$ & 129 & $0.495(0.270-0.672)$ & 126 & 49.4 (45.6 to 53.2 ) & 125 & $0.526(0.512$ to 0.540$)$ \\
\hline Mean $\pm S D$ & $5.6 \pm 1.9$ & & & & & & \\
\hline \multicolumn{8}{|c|}{ Frequency of use of pain medication $(n=516)$} \\
\hline Several times a day & $158(30.6)$ & 136 & $0.491(0.276-0.674) \S$ & 132 & $51.6(48.0$ to 55.2$) \dagger$ & 133 & 0.531 (0.517 to 0.545$) \S$ \\
\hline Every day & $161(31.2)$ & 120 & $0.597(0.351-0.746)$ & 120 & 56.4 (52.8 to 60.0$)$ & 120 & 0.561 (0.546 to 0.575$)$ \\
\hline
\end{tabular}


Table 2 Continued

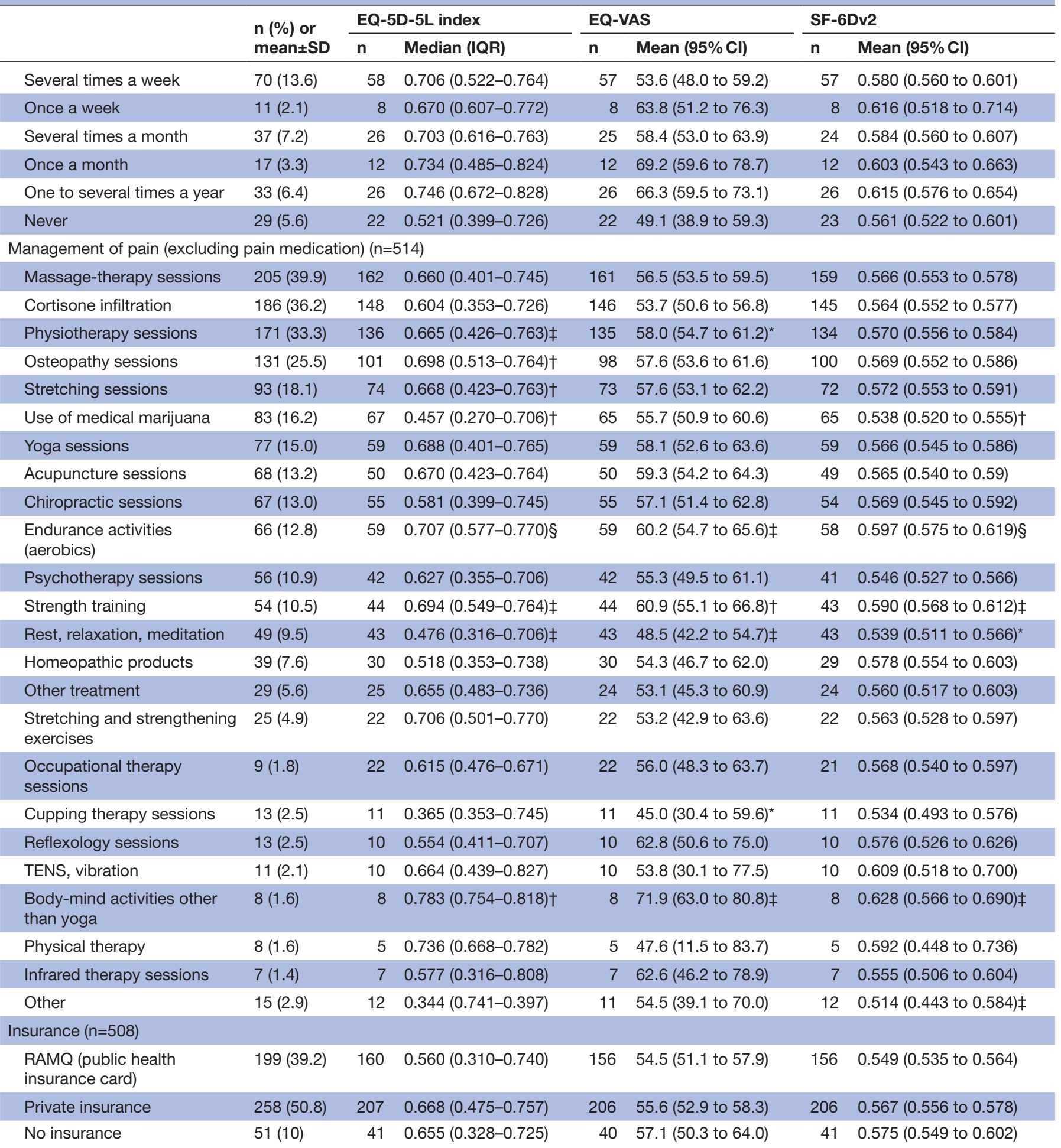

Omnibus test for statistical significance between groups:

${ }^{*} \mathrm{P}<0.1$.

$\dagger P<0.01$.

$\ddagger \mathrm{P}<0.05$.

$\S \mathrm{P}<0.001$.

EQ-5D-5L, EuroQol Five Dimensions; RAMQ, Régie d'Assurance Maladie du Québec; SF-6Dv2, Short Form Six Dimensions version 2; TENS,

Transcutaneous Electrical Nerve Stimulation; VAS, Visual Analogue Scale. 
Table 3 Problems affecting health-related quality of life (HRQoL)

\begin{tabular}{|c|c|}
\hline & n (\%) \\
\hline No problem & $162(32.0)$ \\
\hline Self-reported problems affecting HRQoL & $345(68.1)$ \\
\hline Pain & $307(60.8)$ \\
\hline Fatigue/insomnia & $290(57.4)$ \\
\hline Fatigue & $260(51.5)$ \\
\hline Insomnia & $207(41.0)$ \\
\hline Musculoskeletal disorder & $284(56.2)$ \\
\hline Osteoarthritis & $222(44.0)$ \\
\hline Arthritis & $59(11.7)$ \\
\hline Unintentional injury & $24(4.8)$ \\
\hline Other musculoskeletal disorder & $141(27.9)$ \\
\hline Mental disorder & $222(44.0)$ \\
\hline Anxiety/stress & $198(39.2)$ \\
\hline Depression & $123(24.4)$ \\
\hline Other mental disorder & $27(5.4)$ \\
\hline Cardiac disorder & $138(27.3)$ \\
\hline High blood pressure & $125(24.8)$ \\
\hline Heart disease & $24(4.8)$ \\
\hline Stroke & $5(1.0)$ \\
\hline Endocrine problem & $121(24.0)$ \\
\hline Diabetes & $73(14.5)$ \\
\hline Thyroid disorder & 65 (12.9) \\
\hline Other endocrine problem & $18(3.6)$ \\
\hline Gastrointestinal problem & $135(26.7)$ \\
\hline Digestion disorder & $97(19.2)$ \\
\hline Other gastrointestinal problem & $82(16.2)$ \\
\hline Respiratory disorder & $67(13.3)$ \\
\hline Chronic obstructive pulmonary disease & $8(1.6)$ \\
\hline Other respiratory disorder & $63(12.5)$ \\
\hline Neurological disease & $47(9.3)$ \\
\hline Urogenital disorder & $36(7.1)$ \\
\hline Metabolic problem & $9(1.8)$ \\
\hline Cancer & $14(2.8)$ \\
\hline Migraines, headache & $16(3.2)$ \\
\hline ORL & $6(1.2)$ \\
\hline Other & $17(3.4)$ \\
\hline
\end{tabular}

Five hundred and seven subjects answered if they had a problem affecting their quality of life, but 2 mentioned 'yes' without specifying which ones. So the percentages of each of the problems were calculated on 505 subjects.

$\mathrm{ORL}$, oto-rhino-laryngology.

same condition, even though they are in other regions. Another strength is that no ceiling effect was observed in our cohort for EQ-5D-5L and SF-6Dv2 as it was in the study by Ye $e t a l,{ }^{16}$ but different to the Cheung study that showed
Table 4 Multivariate models to predict EQ-5D-5L, EQ-VAS and SF-6Dv2

\begin{tabular}{|c|c|c|}
\hline & Estimate $\pm S E$ & $P$ value \\
\hline \multicolumn{3}{|c|}{ EQ-5D-5L index $\left(R^{2}=0.5192\right)$} \\
\hline BMI (continuous) & $0.003 \pm 0.001$ & 0.0284 \\
\hline Urban area $(1-0)$ & $-0.046 \pm 0.019$ & 0.0158 \\
\hline Employed (1-0) & $-0.118 \pm 0.023$ & $<0.0001$ \\
\hline Retired (1-0) & $-0.058 \pm 0.021$ & 0.0069 \\
\hline $\begin{array}{l}\text { Good health status } \\
(1-0)\end{array}$ & $-0.057 \pm 0.019$ & 0.0030 \\
\hline $\begin{array}{l}\text { Satisfaction on his/her } \\
\text { health }(0-10)\end{array}$ & $-0.018 \pm 0.005$ & 0.0002 \\
\hline $\begin{array}{l}\text { Satisfaction on his/her } \\
\text { life }(0-10)\end{array}$ & $-0.021 \pm 0.005$ & $<0.0001$ \\
\hline $\begin{array}{l}\text { Intensity of pain today } \\
(0-10 \mathrm{~cm})\end{array}$ & $0.031 \pm 0.006$ & $<0.0001$ \\
\hline $\begin{array}{l}\text { Worst level of pain in } \\
\text { last } 2 \text { weeks }(0-10 \mathrm{~cm})\end{array}$ & $0.013 \pm 0.006$ & 0.0332 \\
\hline $\begin{array}{l}\text { Osteopathy sessions } \\
(1-0)\end{array}$ & $-0.06 \pm 0.02$ & 0.0030 \\
\hline $\begin{array}{l}\text { Body-mind activities } \\
\text { other than yoga }(1-0)\end{array}$ & $-0.162 \pm 0.061$ & 0.0088 \\
\hline \multicolumn{3}{|l|}{ EQ-VAS $\left(R^{2}=0.3571\right)$} \\
\hline $\begin{array}{l}\text { Poor health status } \\
(1-0)\end{array}$ & $-5.812 \pm 2.526$ & 0.0219 \\
\hline $\begin{array}{l}\text { Satisfaction on his/her } \\
\text { health }(0-10)\end{array}$ & $2.482 \pm 0.475$ & $<0.0001$ \\
\hline $\begin{array}{l}\text { Satisfaction on his/her } \\
\text { life }(0-10)\end{array}$ & $1.459 \pm 0.441$ & 0.0010 \\
\hline Osteoporosis (1-0) & $10.299 \pm 3.39$ & 0.0025 \\
\hline $\begin{array}{l}\text { Intensity of pain today } \\
(0-10 \mathrm{~cm})\end{array}$ & $-2.133 \pm 0.427$ & $<0.0001$ \\
\hline \multicolumn{3}{|l|}{ SF-6Dv2 $\left(R^{2}=0.4593\right)$} \\
\hline Have a child (1-0) & $0.022 \pm 0.009$ & 0.0125 \\
\hline Sick leave (1-0) & $-0.028 \pm 0.009$ & 0.0026 \\
\hline $\begin{array}{l}\text { Poor health status } \\
(1-0)\end{array}$ & $-0.041 \pm 0.01$ & $<0.0001$ \\
\hline Fair health status $(1-0)$ & $-0.023 \pm 0.008$ & 0.0022 \\
\hline $\begin{array}{l}\text { Satisfaction on his/her } \\
\text { life }(0-10)\end{array}$ & $0.013 \pm 0.001$ & $<0.0001$ \\
\hline $\begin{array}{l}\text { Worst level of pain in } \\
\text { last } 2 \text { weeks }(0-10 \mathrm{~cm})\end{array}$ & $-0.015 \pm 0.002$ & $<0.0001$ \\
\hline $\begin{array}{l}\text { Body-mind activities } \\
\text { other than yoga (1-0) }\end{array}$ & $0.047 \pm 0.023$ & 0.0393 \\
\hline
\end{tabular}

BMI, body mass index; EQ-5D-5L, EuroQol Five Dimensions; SF6 Dv2, Short Form Six Dimensions version 2; VAS, Visual Analogue Scale.

$14 \%$ for EQ-5D-5L and $1 \%$ for SF-6D. ${ }^{17}$ Another strength is that our study provides utility scores for various sociodemographic data, type of diagnosis and management of pain for subjects with CLBP. For patients with LBP, very few studies present the utility score according to as many 
variables. Most studies present only the global utility score for their cohort and compare the agreement between EQ-5D and SF-6D or compare with specific HRQoL questionnaires for patients with LBP (ie, Owswestry Disability Index and Roland-Morris Disability Questionnaire). ${ }^{16-1848}$

One limitation for calculating EQ-5D-5L and SF-6Dv2 utility scores is that there is no value set for the Quebec population, which does not allow cultural specificities to be considered. Another limitation is that the female population is over-represented in our cohort, although it is recognised that LBP is more prevalent among women. The number of subjects in the survey is acceptable and is more than other studies analysing EQ-5D-5L and SF-6Dv2, but it is not quite enough to have a representative cohort of the Quebec population with LBP (ie, the sample size to be representative of $95 \%$ of the population with a margin of error of $3 \%$ is set at 1003). This may limit the generalisation of the results. Another limitation is that subjects who did not complete the survey up to the EQ-5D-5L and SF-6Dv2 section were older, which may cause this population to be under-represented in utility scores. It is possible that this clientele had more difficulty completing the online questionnaire and abandoned it before the end. Finally, since the AQDC is a patient organisation dedicated to chronic pain and not only to CLBP, we were not able to calculate a response rate to the survey (ie, the survey was sent to all members and not only to CLBP members).

\section{CONCLUSION}

This study described utility scores with EQ-5D-5L and SF-6Dv2 in patients with CLBP in Quebec. Results were similar to other studies with patients with CLBP and in our sense could be used for population comparisons. Also, these values were well below those reported in the Quebec general population and highlight the association between CLBP and HRQoL.

Acknowledgements The authors would like to thank all those who participated in this study, particularly members of the Association québécoise de la douleur chronique. TGP is member of the FRQS-funded Centre de recherche de l'Institut universitaire de santé mentale de Montréal.

Contributors TP conceived, designed and conducted the study, participated to analysis and writing, and revised the manuscript. LW participated to analysis and revised the manuscript. NC participated in the design of the study, participated to analysis and writing, and revised the manuscript.

Funding The authors have not declared a specific grant for this research from any funding agency in the public, commercial or not-for-profit sectors.

Map disclaimer The depiction of boundaries on this map does not imply the expression of any opinion whatsoever on the part of BMJ (or any member of its group) concerning the legal status of any country, territory, jurisdiction or area or of its authorities. This map is provided without any warranty of any kind, either express or implied.

Competing interests None declared.

Patient consent for publication Not required.

Ethics approval This project was approved by the institutional ethics committee (Comité d'éthique de la recherche of the CIUSSS de l'Estrie-CHUS \#2019-2929). The subjects' consent was obtained by having them click on the start button at the end of the explanatory letter. All questionnaires were anonymous, and the data were stored on a protected network at our institution to ensure confidentiality and protection of the respondents.

Provenance and peer review Not commissioned; externally peer reviewed.

Data availability statement All data relevant to the study are included in the article or uploaded as supplementary information. Data are presented in tables and supplementary tables. As per our ethics committee rules, individual-level data will be made available upon reasonable request by email to the corresponding author.

Open access This is an open access article distributed in accordance with the Creative Commons Attribution Non Commercial (CC BY-NC 4.0) license, which permits others to distribute, remix, adapt, build upon this work non-commercially, and license their derivative works on different terms, provided the original work is properly cited, appropriate credit is given, any changes made indicated, and the use is non-commercial. See: http://creativecommons.org/licenses/by-nc/4.0/.

ORCID iD

Thomas G Poder http://orcid.org/0000-0001-7017-096X

\section{REFERENCES}

1 Hartvigsen J, Hancock MJ, Kongsted A, et al. What low back pain is and why we need to pay attention. Lancet 2018;391:2356-67.

2 Badley EM, Millstone DB, Perruccio AV. Back pain and co-occurring conditions: findings from a nationally representative sample. Spine 2018;43:E935-41.

3 Dunn KM, Hestbaek L, Cassidy JD. Low back pain across the life course. Best Pract Res Clin Rheumatol 2013;27:591-600.

4 Allegri M, Montella S, Salici F, et al. Mechanisms of low back pain: a guide for diagnosis and therapy. F1000Res 2016;5:1530-686.

5 Pagé MG, Fortier M, Ware MA, et al. As if one pain problem was not enough: prevalence and patterns of coexisting chronic pain conditions and their impact on treatment outcomes. J Pain Res 2018;11:237-54.

6 Canadian Pain Task Force Report. Chronic pain in Canada: laying a foundation for action, 2019. Available: https://www.canada.ca/en/ health-canada/corporate/about-health-canada/public-engagement/ external-advisory-bodies/canadian-pain-task-force/report-2019.html

7 Hajihasani A, Rouhani M, Salavati M, et al. The influence of cognitive behavioral therapy on pain, quality of life, and depression in patients receiving physical therapy for chronic low back pain: a systematic review. Pm R 2019;11:167-76.

8 Oksuz E, Prevalence OE. Prevalence, risk factors, and preferencebased health states of low back pain in a Turkish population. Spine 2006;31:E968-72.

9 Maher C, Underwood M, Buchbinder R. Non-specific low back pain. Lancet 2017;389:736-47.

10 Moulin DE, Clark AJ, Speechley M, et al. Chronic pain in Canadaprevalence, treatment, impact and the role of opioid analgesia. Pain Res Manag 2002;7:179-84.

11 Schopflocher D, Taenzer P, Jovey R. The prevalence of chronic pain in Canada. Pain Res Manag 2011;16:445-50.

12 Konstantinou K, Dunn KM, Ogollah R, et al. Characteristics of patients with low back and leg pain seeking treatment in primary care: baseline results from the ATLAS cohort study. BMC Musculoskelet Disord 2015;16:332.

13 Hurwitz EL, Randhawa K, Yu H, et al. The global spine care initiative: a summary of the global burden of low back and neck pain studies. Eur Spine J 2018;27:796-801.

14 Weinstein MC, Torrance G, McGuire A. QALYs: the basics. Value Health 2009;12:S5-9.

15 Fauteux V, Poder TG. État des lieux sur les méthodes d'élicitation du QALY [Overview of QALY elicitation methods]. Int J Health Pref Res 2017;1:2-14

16 Ye Z, Sun L, Wang Q. A head-to-head comparison of EQ-5D-5L and SF-6D in Chinese patients with low back pain. Health Qual Life Outcomes 2019;17:57.

17 Cheung PWH, Wong CKH, Cheung JPY. Differential psychometric properties of EuroQoL 5-Dimension 5-Level and shortform 6-Dimension utility measures in low back pain. Spine 2019;44:E679-86.

18 Finch AP, Dritsaki M, Jommi C. Generic preference-based measures for low back pain: which of them should be used? Spine 2016;41:E364-74.

19 Mulhern B, Brazier J. Developing version 2 of the SF-6D: the health state classification system. Qual Life Res 2014;23:49. 
20 Bansback N, Mulhern B, Sawatsky R, et al. Valuing the SF-6Dv2 in Canada. Qual Life Res 2015;24:180-1.

21 Poder TG, Fauteux V, He J, et al. Consistency between three different ways of administering the short form 6 dimension version 2. Value Health 2019;22:837-42.

22 ACMTS. Lignes directrices de l'évaluation économique des technologies de la santé au Canada. 4ème édition. Ottawa: Agence Canadienne des Médicaments et des Technologies de la Santé, 2017.

23 HAS. Choix méthodologique pour l'évaluation économique la HAS. Paris: Haute Autorité de Santé, 2011.

24 Government of Canada. Quebec's provincial symbols. Available: https://www.canada.ca/en/canadian-heritage/services/provincialterritorial-symbols-canada/quebec.html [Accessed 28 Feb 2020].

25 The conference board of Canada. Health. Provincial and territorial ranking. How Canada performs. Available: https://www. conferenceboard.ca/hcp/provincial/health.aspx\#ftn2-ref [Accessed 28 Feb 2020].

26 Secrétariat du Québec aux relations canadiennes. Recognition of the Québec nation. Available: https://www.sqrc.gouv.qc.ca/relationscanadiennes/institutions-constitution/statut-qc/reconnaisancenation-en.asp [Accessed 8 Feb 2020].

27 Poder TG, Beffarat M, Benkhalti M, et al. A discrete choice experiment on preferences of patients with low back pain about non-surgical treatments: identification, refinement and selection of attributes and levels. Patient Prefer Adherence 2019;13:933-40.

28 Reed Johnson F, Lancsar E, Marshall D, et al. Constructing experimental designs for discrete-choice experiments: report of the ISPOR conjoint analysis experimental design good research practices Task force. Value Health 2013;16:3-13.

29 Xie F, Pullenayegum E, Gaebel K, et al. Canadian EQ-5D-5L valuation study group. A time trade-off-derived value set of the EQ-5D-5L for Canada. Med Care 2016;54:98-105.

30 Brazier JE, Roberts J. The estimation of a preference-based measure of health from the SF-12. Med Care 2004;42:851-9.

31 Statistics Canada. Education highlight tables, 2016 census. Available: https://www12.statcan.gc.ca/census-recensement/2016/ $\mathrm{dp}-\mathrm{pd} / \mathrm{hlt}$-fst/edu-sco/Table.cfm?Lang=E\&T=11\&Geo=00\&View=2\& Age $=2$ [Accessed 28 Feb 2020]

32 Statistics Canada. Table 13-10-0445-01 Canadian community health survey (CCHS 1.1 and 2.1) linguistic minority profile (mother tongue and first official language spoken). Available: https://www150.statcan. gc.ca/t1/tbl1/en/tv.action?pid=1310044501 [Accessed 28 Feb 2020].

33 Grochtdreis T, Dams J, König H-H, et al. Health-related quality of life measured with the EQ-5D-5L: estimation of normative index values based on a representative German population sample and value set. Eur J Health Econ 2019;20:933-44.
34 Poder TG. Challenges to make cost-effectiveness studies usable by decision makers. J Thorac Cardiovasc Surg 2018;156:1931-2.

35 Pagé GM, Lacasse A, et al. The Quebec low back pain study: a protocol for an innovative 2-tier provincial cohort. Pain Rep 2020;5:e799.

36 Poder TG, Carrier N, Kouakou CRC. Quebec health-related qualityof-life population norms using the EQ-5D-5L: decomposition by sociodemographic data and health problems. Value Health 2020;23:251-9.

37 Søgaard R, Christensen FB, Videbæk TS, et al. Interchangeability of the EQ-5D and the SF-6D in long-lasting low back pain. Value Health 2009;12:606-12.

38 Balagué F, Mannion AF, Pellisé F, et al. Non-specific low back pain. Lancet 2012;379:482-91.

39 Manchikanti L, Singh V, Falco FJE, et al. Epidemiology of low back pain in adults. Neuromodulation 2014;17:3-10.

40 Leboeuf-Yde C. Body weight and low back pain. A systematic literature review of 56 journal articles reporting on 65 epidemiologic studies. Spine 2000;25:226-37.

41 Shiri R, Solovieva S, Husgafvel-Pursiainen K, et al. The role of obesity and physical activity in non-specific and radiating low back pain: the young Finns study. Semin Arthritis Rheum 2013;42:640-50.

42 Demyttenaere K, Bruffaerts R, Lee S, et al. Mental disorders among persons with chronic back or neck pain: results from the world mental health surveys. Pain 2007;129:332-42.

43 Gore M, Sadosky A, Stacey BR, et al. The burden of chronic low back pain: clinical comorbidities, treatment patterns, and health care costs in usual care settings. Spine 2012;37:E668-77.

44 Hestbaek L, Leboeuf-Yde C, Kyvik KO, et al. Comorbidity with low back pain: a cross-sectional population-based survey of 12- to 22-year-olds. Spine 2004;29:1483-91.

45 Hestbaek L, Leboeuf-Yde C, Manniche C. Is low back pain part of a general health pattern or is it a separate and distinctive entity? A critical literature review of comorbidity with low back pain. $J$ Manipulative Physiol Ther 2003;26:243-52.

46 Reme SE, Tangen T, Moe T, et al. Prevalence of psychiatric disorders in sick listed chronic low back pain patients. Eur J Pain 2011:15:1075-80.

47 Schneider S, Mohnen SM, Schiltenwolf M, et al. Comorbidity of low back pain: representative outcomes of a national health study in the federal Republic of Germany. Eur J Pain 2007;11:387-97.

48 Suarez-Almazor ME, Kendall C, Johnson JA, et al. Use of health status measures in patients with low back pain in clinical settings. Comparison of specific, generic and preference-based instruments. Rheumatology 2000;39:783-90. 